\title{
Erratum to: Response to hydroxycarbamide in pediatric $\beta$-thalassemia intermedia: 8 years' follow-up in Egypt
}

\author{
Amal El-Beshlawy ${ }^{1}$ Mona El-Ghamrawy ${ }^{1}$ Mona Abou EL-Ela ${ }^{1} \cdot$ Fadwa Said $^{1}$. \\ Sonia Adolf ${ }^{2}$ - Abdel-Rahman Ahmed Abdel-Razek ${ }^{1} \cdot$ Rania Ismail Magdy $^{1}$. \\ Amina Abdel-Salam ${ }^{1}$
}

Published online: 14 March 2016

(C) Springer-Verlag Berlin Heidelberg 2016

Erratum to: Annals of Hematology 93(12): 2045-2050

DOI 10.1007/s00277-014-2154-5

The affiliation of Sonia Adolf was missing in the original version of this article. Complete affiliation is presented here.

The online version of the original article can be found at http://dx.doi.org/ 10.1007/s00277-014-2154-5.

$\triangle \quad$ Amal El-Beshlawy amalelbeshlawy@yahoo.com

1 Cairo University, Cairo, Egypt

2 National Research Center, NRC, Cairo, Egypt 